\title{
Driver Preference and Level of Trust Related to Real-Time Road Freezing Risk Information
}

\author{
Moataz Bellah Ben Khedher, ${ }^{1}$ Choong Heon Yang $\left(\mathbb{D},{ }^{2}\right.$ Jin Guk Kim, ${ }^{2}$ Duk Geun Yun, \\ and Sung Pil Shin ${ }^{2}$ \\ ${ }^{1}$ Department of Civil \& Environmental Engineering, KICT School, University of Science and Technology, Daejeon, Republic \\ of Korea \\ ${ }^{2}$ Department of Infrastructure Safety Research, Korea Institute of Civil Engineering and Building Technology, Goyang-si, \\ Gyeonggi-do 10223, Republic of Korea
}

Correspondence should be addressed to Choong Heon Yang; chyang@kict.re.kr

Received 25 November 2019; Revised 22 September 2020; Accepted 15 October 2020; Published 27 October 2020

Academic Editor: Filomena Mauriello

Copyright (C) 2020 Moataz Bellah Ben Khedher et al. This is an open access article distributed under the Creative Commons Attribution License, which permits unrestricted use, distribution, and reproduction in any medium, provided the original work is properly cited.

\begin{abstract}
Bad weather conditions can affect normal driving by substantially hindering visibility. Among all adverse weather conditions, road freezing is probably the most dangerous to drivers because slippery roads reduce surface friction and can lead to loss of vehicle control. This paper evaluates driver preference of receiving real-time road freezing risk information and explores the factors that would most influence drivers' trust in a future road freezing information service. A survey was conducted in the metropolitan areas of South Korea during January and February 2019. The survey was completed by 231 driver's license holders of 18 years or older, and the results were used for statistical analysis. According to the survey results, the variable message sign (VMS) is a very important system from the perspective of public benefit. Car-navigation systems are preferred for age categories of $21 \sim 30$ and over 50. In addition, ordinal regression was used to analyze the causal relationship between the level of trust regarding road freezing risk information and its controlling factors. The ordered log odds of drivers with previous accident experience due to slippery roads exhibit a higher level of trust in road freezing risk information because the coefficient is positive. Moreover, drivers with a constant commute time show a lower level of trust in road freezing risk information. These findings provide a foundation for planning the scope of future road freezing risk information service, as well as the specific service targets and type of information, especially during the winter season.
\end{abstract}

\section{Introduction}

Adverse weather conditions such as heavy snow, torrential rain, and dense fog can greatly affect the road environment and lead to dry, wet, and icy road surface conditions. Most conditions can be seen by drivers while driving; thus, they can react accordingly by adjusting their driving behavior to some extent [1]. However, ice on the road surface cannot be easily seen by drivers because thin layers of ice are transparent and expose the underlying road surface. Reduced pavement friction due to icy roads can unfavorably affect driver safety. According to the U.S. Department of Transportation (USDOT), an average of 156, 164 crashes every year are caused by icy roads [2]. Several studies have demonstrated a significant increase in the accident risk in the presence of snowy and icy roads [3-6]. A report from Close COST Action 353 [7] estimates that the accident risk on European roads may increase by more than six times on snowy roads. Malin et al. [8] identified that the relative accident risk was increased in poor road weather conditions and was highest for freezing rain as well as slippery and very slippery road conditions.

Providing proactive road freezing risk information is one solution for improving driver awareness in slippery road segments, which can allow drivers to maneuver appropriately prior to passing an icy road section. Such information 
could also be disseminated to drivers using several current methods. For example, the variable message signs (VMSs) have been widely used in transportation networks. VMS can assist drivers with real-time traffic conditions and provide route guidance. Many efforts have been made to address issues regarding drivers' response behavior to VMS. Several studies have shown that drivers broadly comply with the guidance [9-13] because they have a high degree of trust in real-time traffic information $[14,15]$. However, the effect of VMS on drivers' behavior strongly depends on the VMS content and display format [16]. Driver response to traffic as well as environmental condition information can be assessed using various approaches such as driving simulators and surveys. With the advent of smartphones, which are supported by GPS (Global Positioning System), many applications (abbreviated here to apps) have been developed to provide real-time traffic information as well as route guidance $[17,18]$. Traffic information based on smartphone apps can be made available to drivers at any time and on a large transportation network scale, unlike VMS, which is restricted to specific sites with localized information. However, smartphone apps are limited to images and/or maps, whereas guidance apps provide route guidance to drivers to enable detour around traffic congestion and/or road hazards such as work zones. Unfortunately, few studies have rigorously examined drivers' response to traffic information provided via smartphone apps. The only relevant research conducted in Malaysia [18] concluded that accurate real-time traffic information on incident and routing advice is an important app feature that affects its acceptance. Interestingly, the sociodemographic characteristics of drivers tend to have less influence on traffic app adoption.

Issues related to driver responses to real-time road freezing risk information have not yet been studied in detail. In previous research, a model for estimating road surface temperature changes according to weather conditions was developed based on a machine learning technique [19-22]. In South Korea, a road surface freezing risk information service is planned based on the results of this model, which will provide real-time messages such as "Caution Road Surface Freezing Ahead" to drivers.

The purpose of this research is to determine drivers' preferred methods of receiving road freezing risk information and the factors that most influence drivers' trust in the information provided by the proposed road freezing risk information service. The results can provide very important insights for determining future service targets, service scope, information dissemination methods, and so on. For this, a questionnaire is developed for participants with a driver's license over 18 years of age and of both sexes. The survey results are carefully analyzed, and an ordinal logistic regression is developed to identify the factors that strongly affect drivers' trust in real-time road freezing risk information. The remainder of this paper is structured as follows. Section 2 presents the overall research procedure used in this study including survey design and analysis approach. Sections 3 shows the statistical analysis results following by a discussion. Finally, in Section 4, the conclusions and insights of this research are addressed according to its practical applications.

\section{Methodology}

2.1. Survey Design. A specific questionnaire was designed to examine driver's preference regarding the method of receiving road freezing risk information and to determine the factors that most influence the level of trust in the information provided as part of a road freezing information service. The survey was conducted in the metropolitan areas of South Korea during January and February 2019. The survey was performed on drivers who satisfy two main conditions. The first one is that the respondent must have their own driving license, which also indicates that age is legally 18 years or older. The second is that they have to drive regularly, at least twice a week. A total of 231 respondents completed the survey, the results of which were used for statistical analysis.

The questionnaire was composed of three parts. The first part represents demographic factors. Socioeconomic characteristics of the respondents include gender, age, level of education, annual mileage, driving experience, occupation, and type of vehicle such as private or commercial. The second part addresses the travel characteristics of the drivers. This includes accident experience related to slippery roads; trip purpose such as work, leisure, commute, or other; personal route choice patterns (based on real-time traffic information, previous experience, both, or simply familiar routes); familiarity; driving behavior (compliance with speed limit, adapting to surrounding travel speed for smooth traffic flow rather than speed limit, or generally careful driving); and commute time. For personal route choice pattern variable, our alternatives were established based on previous research [23]. All questions were designed with multiple choice selections. In the final part, drivers were asked how much they would trust various types of road freezing risk information, if provided in real-time, using a predefined scale of "low," "moderate," or "high." In addition, drivers were asked to indicate their preferences for different methods of receiving road freezing risk information including a car-navigation system, smartphone apps, and VMS. The personal information collected through the survey was used for research purposes only and was not disclosed in anyway.

2.2. Data Description. Trained interviewers visited different locations including universities, department stores, subway stations, and public transit companies. They are well trained and qualified since they work at specialized private survey companies. They have lots of experience in relevant works, especially government projects. Before asking the face-toface interview questions, they asked respondents whether they were willing to participate in the interview. If they agreed, the interviewers initiated the main interview, including questions on socioeconomic data, which the respondents completed on their own. Of the 231 respondents who completed the survey, $78.8 \%$ were male, of which $74.9 \%$ were 40 or older. $55 \%$ of respondents had their own vehicles and $84.4 \%$ had more than five years of driving experience. The educational background varied significantly; $32 \%$ had 
attended graduate school, $29.4 \%$ had a college degree, and $38.5 \%$ had graduated high school. As for occupation, $69.7 \%$ of drivers were professionals and $23.8 \%$ had general jobs. Table 1 shows all socioeconomic and travel characteristics of the survey respondents.

The survey results also provided insights into drivers' preferred methods of receiving road freezing risk information. As shown in Figure 1, commercial vehicle drivers have a vastly lower preference for smartphone apps than private vehicle drivers. This is likely because commercial vehicle drivers have much longer operating hours than private vehicle drivers and are thus more sensitive to being prosecuted for smartphone use while driving, which is illegal in South Korea. Private vehicle drivers, on the other hand, have a fairly low preference for VMS, which suggests that they are more sensitive to real-time issues with sections of the roadway rather than certain points on the roadway. Female drivers have a relatively low preference for VMS, perhaps because they are typically more reliant on route guidance provided by car-navigation systems in South Korea [24]. Car-navigation systems are the most preferred method for age categories of 21-30 and over 50, whereas high school graduates have a low preference for smartphone apps, potentially because most commercial vehicle drivers are high school graduates.

2.3. Regression Approach. In this section, we try to identify the factors that most influence the level of drivers' trust in the information provided by the proposed road freezing risk information service. In order to do so, statistical approaches were employed. Various statistical approaches can be used to identify the explanatory variables related to a given outcome variable, as well as the magnitude of the effect of each variable. These include various regression models. Basically, a linear regression model is a set of statistical approaches for estimating the relationship between variables. It contains a large number of techniques for analyzing variables and focuses on the relationship between a dependent variable and one or more independent variables. This approach, however, is limited to conditions where the dependent variable is quantitative and the fixed independent variable has a normal distribution. It is particularly unsuitable when the dependent variable is qualitative.

In this case, a logistic regression approach is more suitable because it can perform statistical modeling using three types of dependent variables. The first approach, called binary logistic regression, corresponds to the case where the variable includes only two classes (a dichotomous outcome). For example, two classes can be described by the presence or absence of a given characteristic or the success or failure of an event. The second approach is multinomial logistic regression, which can address the cases where the variable to be explained has more than two classes and they cannot be ordered or we do not expect to consider the order. This is the case when an individual belongs to a given category or selects an answer to a question from multiple given proposals. Lastly, the third approach is ordinal regression, which is a type of regression analysis used for predicting an ordinal value. Here, the value of the variable exists on an arbitrary scale where the relative ordering between different values is important.

As we define the dependent variable as the level of trust in the information, using a scale of low, moderate, or high, the values can be ordered to determine the ordinal relationship. Therefore, the ordinal regression approach is employed to determine the factors that most affect the level of trust in the information provided through the road freezing information service.

Ordinal regression has been widely used to address related transportation issues. Dabbour et al. [25] applied ordinal regression to determine the key factors affecting drivers' injury severity resulting from collision accidents between motor vehicles and trains. They developed fixedparameter and random-parameter ordered regression models based on data acquired over a period of 15 years. Cherry and Townsend [26] proposed improvement recommendations for metro-bus transfers in Bangkok based on survey responses. The authors analyzed the survey results using Importance-Satisfaction (I/S) analysis and ordinal regression to identify the main required improvements in transit quality according to user perception. Zmud et al. [27] used a survey to explore the significant factors that influence people's willingness to adopt selfdriving vehicles and analyzed the results using an ordinal regression model. Wang et al. [28] performed ordinal regression analysis on survey data to explore the potential of car sharing solutions in Shanghai. Their results showed more interest in car sharing from the younger generation, long-distance commuters, and people with higher educational backgrounds. Zhong et al. [23] used ordinal regression to explore the main factors influencing drivers' guidance compliance with road condition information provided through VMS. The data were analyzed by plotting on Microsoft Excel package, and regression models were developed using regression statistical techniques performed on SPSS version 18.0 [29].

The ordinal logistic regression model can be used to predict the cumulative probability of the level of trust in road freezing information being less than or equal to a certain level. Let $P_{1}=$ probability of low trust, $P_{2}=$ probability of medium level of trust, and $P_{3}=$ probability of high trust; the cumulative probability can be expressed by the following equation [30]:

$$
T_{j}=\frac{e^{\alpha_{j}+\beta_{1} X_{1}+\cdots+\beta_{k} X_{k}}}{1+e^{\alpha_{j}+\beta_{1} X_{1}+\cdots+\beta_{k} X_{k}}}
$$

where $T_{j}$ is the cumulative probability of trust level, $X_{i}$ are the independent variables, $\alpha_{j}$ and $\beta_{k}$ are the regression coefficients, and $T_{1}=P_{1}, \quad T_{2}=P_{1}+P_{2}, \quad$ and $T_{3}=P_{1}+P_{2}+P_{3}=1$. In case of logistic regression, the odds of an event, which represents the ratio of probability that certain event will occur to the probability that it will not occur, is more preferred than the cumulative probability. In other words, a representation of $T_{j} /\left(1-T_{j}\right)$ would be favorable. Therefore, based on equation (1), the odds ratio can be expressed as follows: 
TABLE 1: Socioeconomic and travel characteristics of survey respondents.

\begin{tabular}{|c|c|c|}
\hline Variable & Category & Percentage \\
\hline \multirow{2}{*}{ Gender } & Male & 78.8 \\
\hline & Female & 21.2 \\
\hline \multirow{4}{*}{ Age } & $21-30$ & 6.9 \\
\hline & $31-40$ & 18.2 \\
\hline & $41-50$ & 36.8 \\
\hline & $>50$ & 38.1 \\
\hline \multirow{2}{*}{ Type of vehicle } & Private & 55.0 \\
\hline & Commercial & 45.0 \\
\hline \multirow{3}{*}{ Driving experience } & $<1$ year & 4.8 \\
\hline & $1-5$ years & 10.8 \\
\hline & $>5$ years & 84.4 \\
\hline \multirow{2}{*}{ Accident experience } & Yes & 29.4 \\
\hline & Not available & 70.6 \\
\hline \multirow{4}{*}{ Trip purpose } & Business & 39.4 \\
\hline & Leisure & 10.4 \\
\hline & Commute & 38.5 \\
\hline & Other & 11.7 \\
\hline \multirow{4}{*}{ Route choice patterns } & Based on traffic information & 32.0 \\
\hline & Based on personal experience and traffic information & 51.5 \\
\hline & Based on personal experience & 7.8 \\
\hline & Based on familiarity regardless of other factors & 8.7 \\
\hline \multirow{3}{*}{ Familiarity } & Familiar & 84.0 \\
\hline & Normal & 13.9 \\
\hline & Not familiar & 2.2 \\
\hline \multirow{2}{*}{ Commute time } & Constant & 68.4 \\
\hline & Not constant & 31.6 \\
\hline \multirow{3}{*}{ Driving behavior } & Respects rules & 32.9 \\
\hline & Adheres to surrounding traffic speed & 63.2 \\
\hline & Drives carefully & 3.9 \\
\hline \multirow{3}{*}{ Level of education } & High school & 38.5 \\
\hline & University & 29.4 \\
\hline & Graduate school & 32.0 \\
\hline \multirow{4}{*}{ Occupation } & Self-employed & 1.3 \\
\hline & General jobs & 23.8 \\
\hline & Student & 5.2 \\
\hline & Professionals & 69.7 \\
\hline \multirow{2}{*}{ Annual mileage } & $\geq 10000 \mathrm{~km}$ & 65.8 \\
\hline & $<10000 \mathrm{~km}$ & 34.2 \\
\hline
\end{tabular}

$$
\frac{T_{j}}{\left(1-T_{j}\right)}=e^{\alpha_{j}+\beta_{1} X_{1}+\cdots+\beta_{k} X_{k}}
$$

Finally, by taking the logarithm at both sides, equation (2) transforms to the following:

$$
\log \left(\frac{T_{j}}{1-T_{j}}\right)=\alpha_{j}+\beta_{1} X_{1}+\cdots+\beta_{k} X_{k} .
$$

Before conducting the regression, an analysis of independent variables is performed. A chi-square test is performed to identify the variables that have a causal relationship between the independent variables and dependent variable. Only the independent variables with $p$ values of less than 0.05 will be used for further analysis. After that, collinearity diagnosis is required. Similar to linear regression, ordinal regression is very sensitive to the collinearity among independent variables; thus, collinearity will be tested to select the final independent variables. Ordinal regression generally assumes that there is no fundamental relationship among independent variables. In the regression model, the tolerance and variance inflation factor (VIF) will be the indexes used to test collinearity. If tolerance $>0.1$ and VIF $<10$, then multicollinearity issues are not considered. The overall procedure of statistical analysis used in this study is shown in Figure 2.

\section{Results and Discussion}

3.1. Preliminary Analysis. Many factors influence a driver's level of trust level in road freezing risk information, including personal characteristics, such as age, gender, and occupation, and travel characteristics such as trip purpose, route choice patterns, familiarity, commute time, 


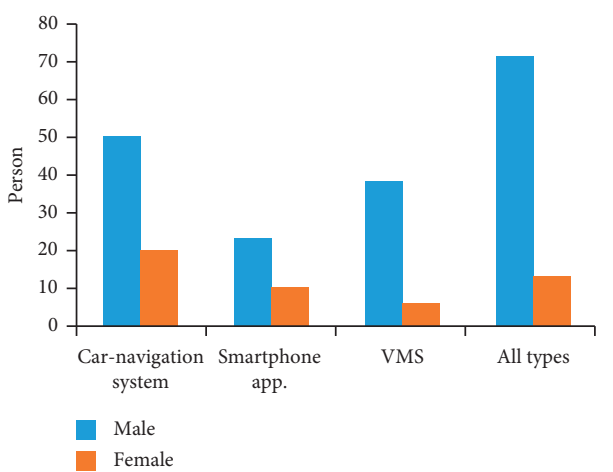

(a)

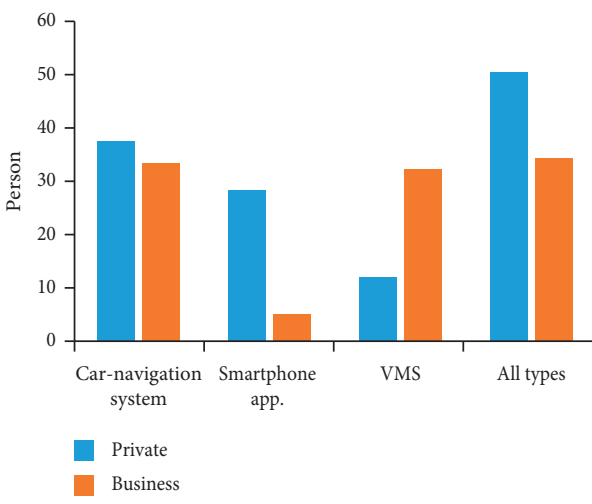

(c)

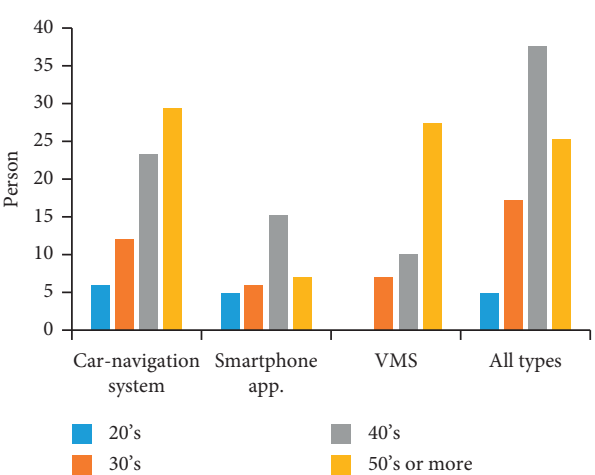

(b)

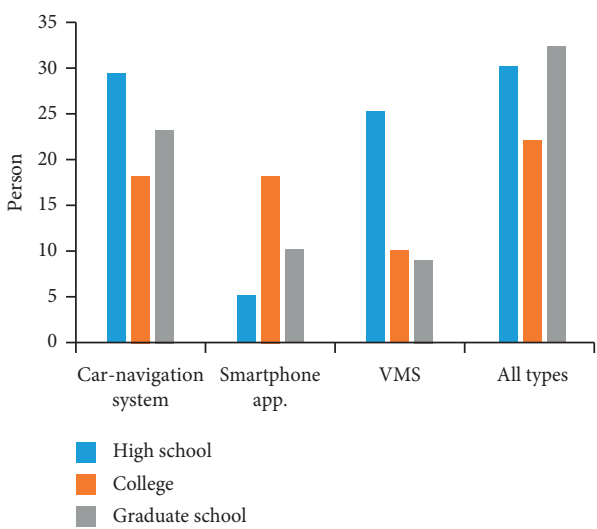

(d)

Figure 1: Preference for receiving road freezing risk information by (a) gender, (b) age, (c) type of vehicle, and (d) level of education.

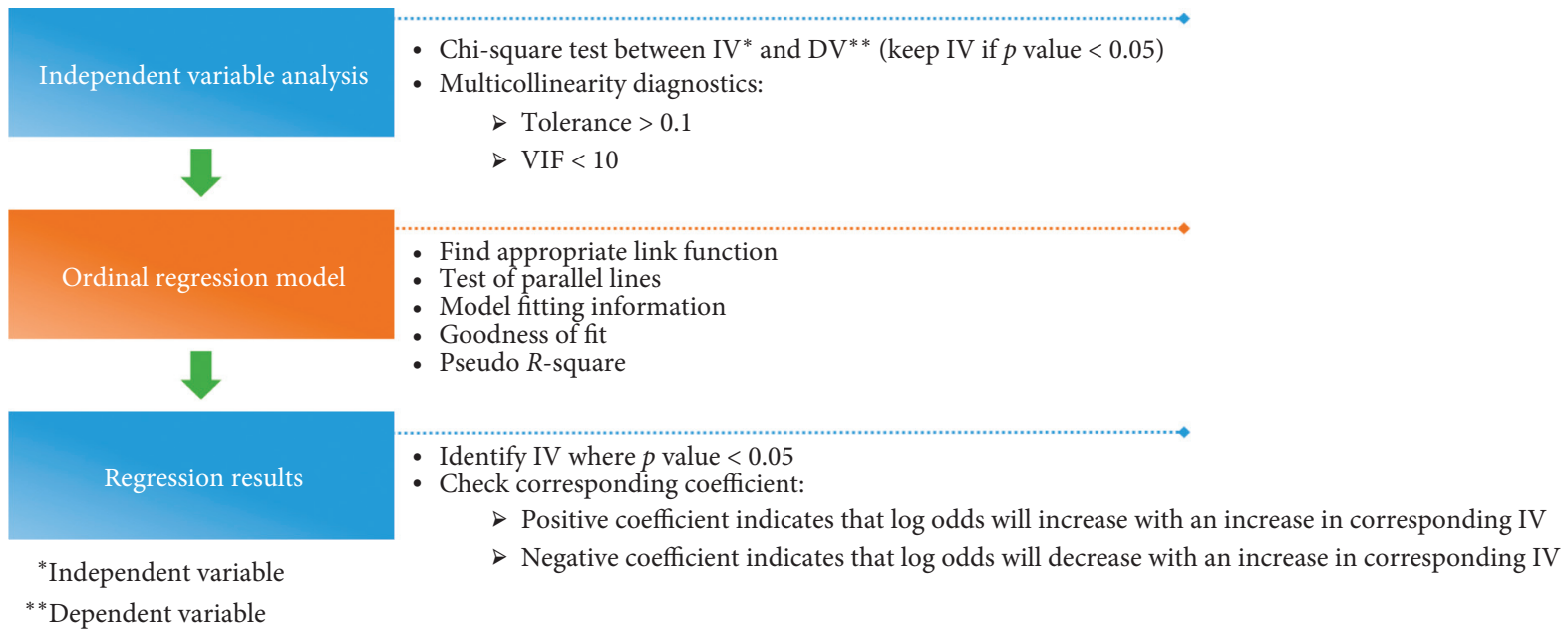

FIGURE 2: Overall statistical analysis procedure.

and driving behavior. These factors were the source of the independent variables in the independent variable in the ordinal regression as represented in Table 2. Their scale of measurement is all nominal.

The independent variables were set to 13 , and the dependent variable was defined as the level of trust in the road freezing risk information provided in Table 2. Figure 3 shows the distribution of the dependent variable by gender, age, vehicle type, and level of education.

A chi-square test was performed to identify the causal relationship between the independent variables and dependent variable before the regression analysis as depicted in Table 3. Only the independent variables with $p$ values of less than 0.05 were employed as the candidate variables, which were the type of vehicle $(p \leq 0.001)$, accident experience 
TABLE 2: Values of variables used in the ordinal regression.

\begin{tabular}{|c|c|}
\hline Independent variable & Range \\
\hline Gender & $\begin{array}{l}\text { 1: male } \\
2: \text { female }\end{array}$ \\
\hline Age & $\begin{array}{l}1: 21-30 \\
2: 31-40 \\
3: 41-50 \\
4:>50\end{array}$ \\
\hline Type of vehicle & $\begin{array}{l}\text { 1: private } \\
\text { 2: commercial }\end{array}$ \\
\hline Driving experience & $\begin{array}{l}1:<1 \text { year } \\
2: 1-5 \text { years } \\
3:>5 \text { years }\end{array}$ \\
\hline Accident experience & $\begin{array}{l}1: \text { yes } \\
2: \text { no }\end{array}$ \\
\hline Trip purpose & $\begin{array}{l}\text { 1: business } \\
\text { 2: leisure } \\
\text { 3: commute } \\
\text { 4: other }\end{array}$ \\
\hline Route choice patterns & $\begin{array}{l}\text { 1: based on real-time traffic information } \\
\text { 2: based on both personal experience and real-time traffic information } \\
\text { 3: based on personal experience } \\
\text { 4: based on familiarity regardless of other factors }\end{array}$ \\
\hline Familiarity & $\begin{array}{l}\text { 1: familiar } \\
\text { 2: normal } \\
\text { 3: not familiar }\end{array}$ \\
\hline Commute time & $\begin{array}{l}\text { 1: constant } \\
\text { 2: not constant }\end{array}$ \\
\hline Driving behavior & $\begin{array}{l}\text { 1: respects rules } \\
\text { 2: adheres to surrounding traffic speed } \\
\text { 3: drives carefully }\end{array}$ \\
\hline Level of education & $\begin{array}{l}\text { 1: high school } \\
\text { 2: university } \\
\text { 3: graduate school }\end{array}$ \\
\hline Occupation & $\begin{array}{l}\text { 1: self-employed } \\
\text { 2: general jobs } \\
\text { 3: student } \\
\text { 4: professional }\end{array}$ \\
\hline Annual mileage & $\begin{array}{l}1: \geq 10000 \mathrm{~km} \\
2:<10000 \mathrm{~km}\end{array}$ \\
\hline Level of trust & $\begin{array}{l}\text { 1: low } \\
\text { 2: medium } \\
\text { 3: high }\end{array}$ \\
\hline
\end{tabular}

( $p=0.015)$, commute time $(p=0.003)$, level of education $(p \leq 0.001)$, and annual mileage $(p=0.011)$. These variables have a significant causal relationship with the dependent variables.

In the regression model, the tolerance and variance inflation factor (VIF) estimated by SPSS are the indexes used to test collinearity. SPSS, however, does not provide these indexes when ordinal regression is employed. Because we are interested in the collinearity of the independent variables, we take advantage of the fact that tolerance and VIF are unrelated to the function form of the dependent variable. These two indexes were estimated using a linear regression model consisting of the same independent variables and dependent variable. All tolerances were more than 0.1 , and all VIFs were less than 10 as shown in Table 4; thus, there was no obvious collinearity among the independent variables, so all variables in Table 4 were employed in the ordinal regression model.

3.2. Model Description. In general, a link function has to be confirmed to apply the ordinal regression model. SPSS provides five link functions: cauchit, complementary log-log, logit, negative log-log, and probit. Constructing a regression model typically involves the use of various link functions to generate a pool of candidate models. SPSS tests the proportional odds assumption, which is commonly referred to as the test of parallel lines. This is because the null hypothesis states that the slope coefficients in the model are the same 

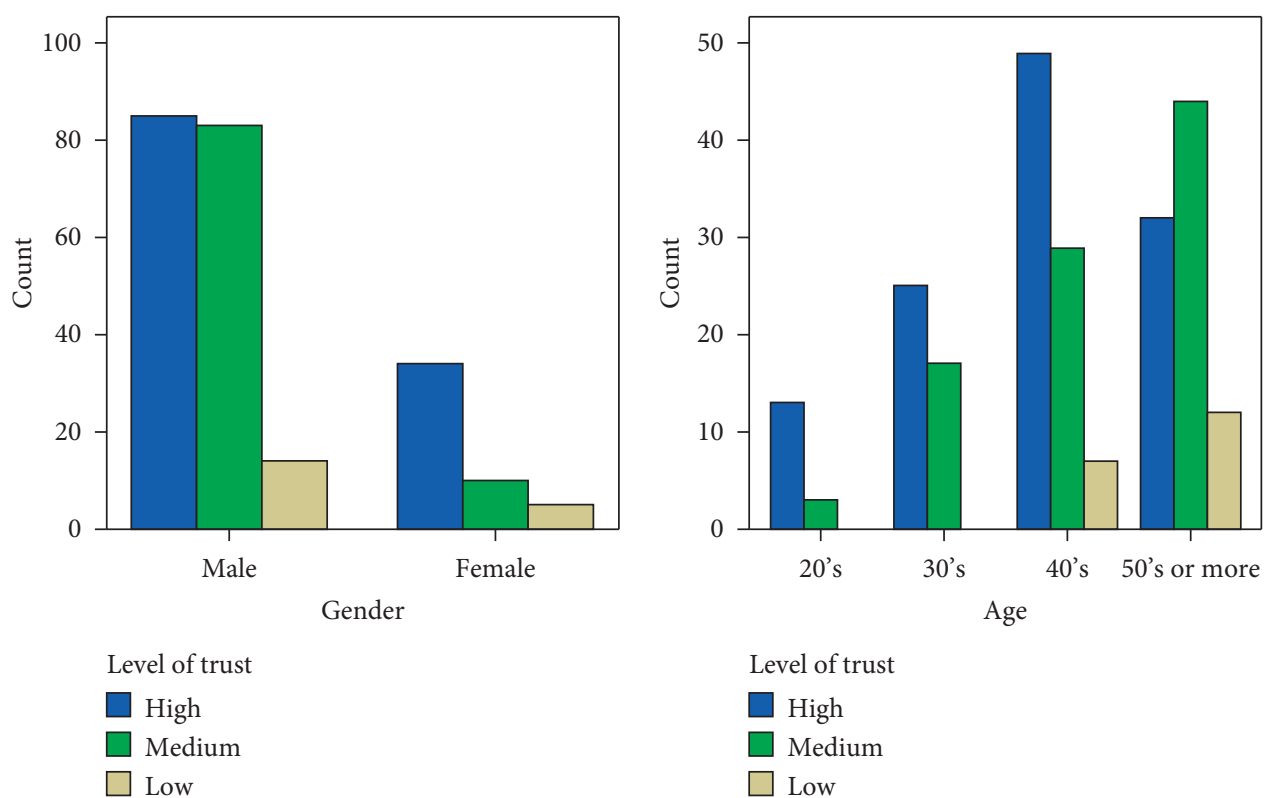

$$
\begin{aligned}
& \text { Level of trust } \\
& \square \text { High } \\
& \square \text { Medium } \\
& \square \text { Low }
\end{aligned}
$$

(a)

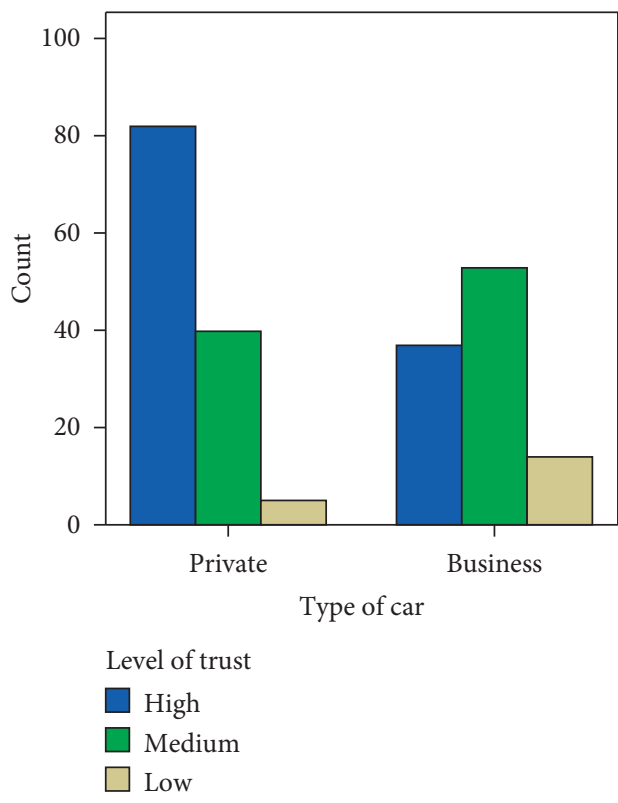

(c)

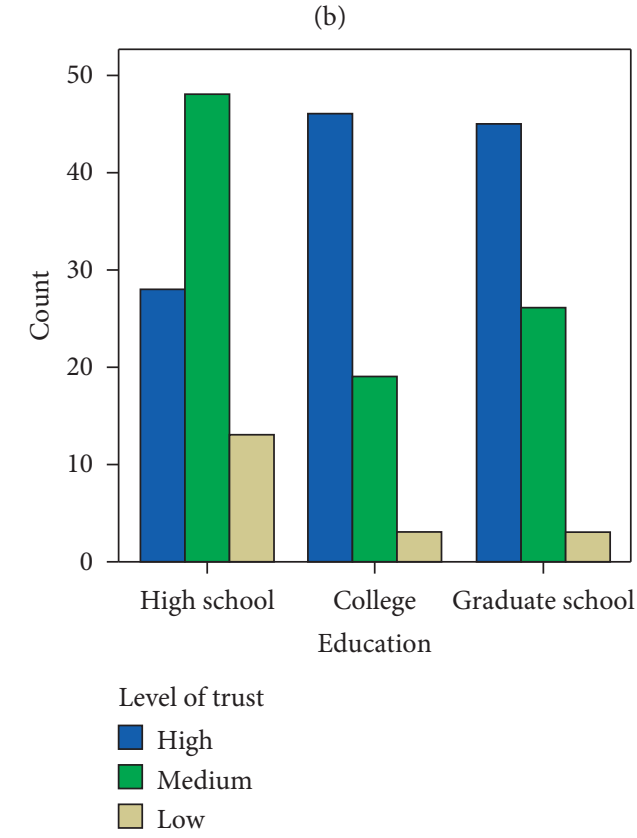

(d)

Figure 3: Level of trust of road freezing risk information by (a) gender, (b) age, (c) type of vehicle, and (d) level of education.

across response categories. As the ordered logit model estimates one equation over all levels of the dependent variable, the test for proportional odds tests whether our oneequation model is valid. If we were to reject the null hypothesis based on the significance of the chi-square statistic, it can be concluded that ordered logit coefficients are not equal across the levels of the outcome, and we would fit a less restrictive model. If we fail to reject the null hypothesis, then the assumption holds. The logit link function is recommended because it yields the best results. As seen from Table 5, the statistical significance level of the general model is 0.819 , so the parallelism assumption could not be rejected. As a result, the ordinal regression is deemed suitable. In addition, Table 5 indicates whether the final model with independent variables provides an improvement over the model without any independent variables. The following null hypothesis is made to provide the fitting information of the model: all the regression coefficients are zero except constant items.

The statistically significant chi-square statistic $(p<0.05)$ indicates that our final model provides a significant enhancement over the model without any independent variables. The null hypothesis is rejected, and no regression coefficients are zero at the same time. These statistics attempt to test the consistency of the observed data with the fitted model. The null hypothesis states that the model is good. The 
TABLE 3: Results of the chi-square test.

\begin{tabular}{lc}
\hline Independent variables & $p$ value \\
\hline Gender & Not available \\
Age & Not available \\
Type of vehicle & $p \leq 0.001$ \\
Driving experience & Not available \\
Accident experience & 0.015 \\
Trip purpose & Not available \\
Route choice patterns & Not available \\
Familiarity & Not available \\
Commute time & 0.003 \\
Driving behavior & Not available \\
Level of education & $p \leq 0.001$ \\
Occupation & Not available \\
Annual mileage & 0.011 \\
\hline
\end{tabular}

TABLE 4: Collinearity statistics of independent variables.

\begin{tabular}{lccc}
\hline Model & Collinearity statistics & & VIF \\
& Tolerance & 3.427 & Yes \\
\hline Type of vehicle & 0.292 & 1.022 & Yes \\
Accident experience & 0.978 & 1.082 & Yes \\
Commute time & 0.924 & 2.926 & Yes \\
Level of education & 0.342 & 1.333 & Yes \\
Annual mileage & 0.750 & & \\
\hline
\end{tabular}

TABLE 5: Details of the regression model.

\begin{tabular}{lcccc}
\hline Model & -2 log likelihood & Chi-square & df & Sig. \\
\hline Test of parallel lines & & & & \\
Null hypothesis & 123.908 & - & - & - \\
General & 120.993 & 2.915 & 6 & 0.819 \\
\hline Model fitting information & 164 & & & \\
Intercept only & 123.908 & 40.092 & 6 & 0 \\
Final & & & & \\
\hline Pseudo $R$-square & & 0.159 & & \\
Cox and Snell & & 0.19 & & \\
Malgelkere & & 0.095 & & \\
McFadden & & & & \\
\hline Goodness of fit & Chi-square & Df & & Sig. \\
Pearson & 66.418 & 56 & 0.161 \\
Deviance & 56.874 & 56 & 0.442 \\
\hline
\end{tabular}

Pearson statistical significance level and the deviance are 0.161 and 0.442 , respectively, so we accept the assumption that there is no distinct difference between predicted and observed values. Unlike linear regression, it is not possible to compute the $R$-squared value for logistic regression models. Instead, three approximation values (Cox and Snell, Nagelkerke, and McFadden) are calculated to evaluate the ability of the model to explain the variations in the data. The larger the pseudo $R$ squared value, the better the model fitting. Cox and Snell (0.159), Nagelkerke, (0.190), and McFadden (0.095) values indicate that the majority of variations in the outcome variables are accounted for by the predictor variables.
3.3. Regression Results. Table 6 summarizes the parameter estimation results including logit regression coefficients, $p$ values of the coefficients, and the $95 \%$ confidence interval for regression coefficients. A significant regression coefficient indicates that the corresponding variable is closely related to the log odds. Namely, the corresponding factor has a close relationship with the level of trust in the road freezing risk information provided. Additionally, positive significant coefficients imply that the log odds will increase with increase of the corresponding independent variable while other variables remain constant. Conversely, negative significant coefficients imply that the log odds will decrease with an increase of the corresponding independent variable while other variables remain constant. Based on the regression results, the following model, in the form of equation (3), was developed for the level of trust in road freezing information.

$$
\log \left(\frac{T_{j}}{1-T_{j}}\right)=\alpha_{j}+0.74 \times \text { acc_experience }-0.703 \text { const_-time, }
$$

where $\alpha_{1}=-0.173, \alpha_{2}=2.491$, acc_experience $=$ previous experience of having a road accident related to slippery roads, and const_time $=$ constant commute time.

Two independent variables, accident experience ( $p=$ $0.012)$ and commute time $(p=0.018)$, are significant at the $p=0.05$ level, whereas other variables are not statistically significant. Therefore, accident experience and commute time are the most important factors influencing the level of trust in the provided road freezing risk information. Other independent variables such as type of vehicle, level of 
TAвLE 6: Level of trust in road freezing information: ordinal logistic regression model estimation results.

\begin{tabular}{|c|c|c|c|c|c|c|c|}
\hline Independe & ariable & Estimate & Sig. & $\begin{array}{l}95 \% \\
\text { ir }\end{array}$ & $\begin{array}{l}\text { dence } \\
\text { al }\end{array}$ & & \\
\hline & & $=0367$ & 0473 & -1371 & 0637 & & \\
\hline Type of vehicle & $\begin{array}{l}\text { Private } \\
\text { Commercial }\end{array}$ & $\begin{array}{c}-0.36 / \\
0^{a}\end{array}$ & $\begin{array}{c}0.4 / 3 \\
.\end{array}$ & $\begin{array}{c}-1.3 / 1 \\
.\end{array}$ & $\begin{array}{c}0.637 \\
.\end{array}$ & & \\
\hline Accident experience & $\begin{array}{c}\text { Yes } \\
\text { Not available }\end{array}$ & $\begin{array}{c}0.740 \\
0^{a}\end{array}$ & $\begin{array}{c}0.012 \\
.\end{array}$ & $\begin{array}{c}0.163 \\
.\end{array}$ & $\begin{array}{c}1.316 \\
.\end{array}$ & & \\
\hline Commute time & $\begin{array}{c}\text { Constant } \\
\text { Not constant }\end{array}$ & $\begin{array}{c}-0.703 \\
0^{\mathrm{a}}\end{array}$ & $\begin{array}{c}0.018 \\
.\end{array}$ & $\begin{array}{c}-1.286 \\
.\end{array}$ & $\begin{array}{c}-0.120 \\
.\end{array}$ & & \\
\hline & High school & 0.672 & 0.230 & -0.426 & 1.770 & & \\
\hline Level of education & $\begin{array}{l}\text { University } \\
\text { Graduate school }\end{array}$ & $\begin{array}{c}-0.475 \\
0^{a}\end{array}$ & $\begin{array}{c}0.240 \\
.\end{array}$ & $\begin{array}{c}-1.268 \\
.\end{array}$ & $\begin{array}{c}0.317 \\
.\end{array}$ & & \\
\hline Annual mileage & $\begin{array}{l}\geq 10000 \mathrm{~km} \\
<10000 \mathrm{~km}\end{array}$ & $\begin{array}{c}0.181 \\
0^{\mathrm{a}}\end{array}$ & $\begin{array}{c}0.605 \\
.\end{array}$ & $\begin{array}{c}-0.505 \\
.\end{array}$ & $\begin{array}{c}0.866 \\
.\end{array}$ & & \\
\hline
\end{tabular}

Link function: logit. The significance of bold values is less than $0.05 .{ }^{a}$ This parameter is set to zero because it is redundant.

education, and annual mileage have less or no impact on determining the trust level of information provided. The ordered log odds of drivers who had previous accident experience due to slippery roads exhibit a higher level of trust in road freezing risk information because the coefficient is positive. Moreover, drivers who have a constant commute time have less trust in road freezing risk information, indicated by the negative coefficient. This reflects the fact that drivers who have experienced a slippery road related accident understand the importance of road freezing risk information more than those with no similar experience. In addition, drivers with a consistent commuting time always travel on the same route at the same time, so they feel that they have a good understanding and prior knowledge of road conditions. Therefore, their understanding of the importance of road freezing risk information tends to be low.

\section{Conclusion}

This research analyzed driver preferences and trust levels related to providing road freezing risk information. In the near future, road freezing risk information in South Korea will be provided in the form of an information service based on a model that is capable of estimating road surface temperature changes, which was developed in previous research by the authors. The key insight of this study is that drivers of commercial vehicles such as freight, regular buses, and shuttle buses do not want to receive information through smartphone apps and instead prefer to receive information via a car-navigation system, VMS, or even a smartphone app combined with the other methods. Any observed preference for receiving information by gender is biased by the fact that the ratio of male respondents was much higher than that of female respondents. Regardless of gender, drivers have a high preference for car-navigation systems as information dissemination method. The use of smartphones during driving is illegal in South Korea, and thus drivers can be prosecuted if they violate these regulations. As a result, the preference for receiving road freezing risk information through smartphones is rather low. According to the survey results, the VMS is very important system for providing real-time traffic information to drivers. However, the primary purpose of the VMS is to provide real-time traffic information such as average speed and upcoming incidents. But the location interval between VMS displays is relatively large. VMS is usually operated on roads that suffer from heavy congestion; thus, effects of providing road freezing risk information based on current VMS may be limited because road freezing has a greater potential risk at low traffic volumes and high travel speeds. This has been proven by various studies in South Korea $[31,32]$. However, the strategic operation of mobile VMS on major arterial roads and freeways with frequent road surface freezing could maximize the effects of the delivered information.

Furthermore, we explored the factor that has the greatest impact on the level of drivers' trust in the provided road freezing risk information. Independent variables and dependent variables were established based on the results of the survey and used as part of an ordinal regression approach. The ordinal regression analysis indicated that drivers' previous ice-related accident experience had the greatest effect on the perceived reliability of road freezing risk information. Commute time also had a high impact, but the level of trust in provided information was lower for drivers with a relatively constant commuting time. The results of the analysis can be useful for determining the scope, specific service targets, and dissemination method of the proposed road freezing risk information service, especially during the winter season.

Currently, it is not possible to operate a full road freezing information service both domestically and internationally. However, this research provides key insights required to specify a future full-scale service business model.

\section{Data Availability}

The questionnaire survey data used to support the findings of this study have not been made available because collected data are confidential. 


\section{Conflicts of Interest}

The authors declare that there are no conflicts of interest regarding the publication of this paper.

\section{Acknowledgments}

This research was supported by a grant from the Inner Research Program funded by the Korea Institute of Civil Engineering and Building Technology.

\section{References}

[1] J. B. Edwards, "Speed adjustment of motorway commuter traffic to inclement weather," Transportation Research Part F: Traffic Psychology and Behaviour, vol. 2, no. 1, pp. 1-14, 1999.

[2] Federal Highway Administration, US Department of Transportation, How do Weather Events Impact Roads?, Philadelphia, PA, USA, 2019, https://ops.fhwa.dot.gov/weather/ q1_roadimpact.htm.

[3] J. Andrey, B. Mills, M. Leahy, and J. Suggett, "Weather as a chronic hazard for road transportation in Canadian cities," Natural Hazards, vol. 28, no. 2/3, pp. 319-343, 2003.

[4] R. Bergel-Hayat, M. Debbarh, C. Antoniou, and G. Yannis, "Explaining the road accident risk: weather effects," Accident Analysis \& Prevention, vol. 60, pp. 456-465, 2013.

[5] A. W. Black and T. L. Mote, "Effects of winter precipitation on automobile collisions, injuries, and fatalities in the United States," Journal of Transport Geography, vol. 48, pp. 165-175, 2015.

[6] T. Brijs, D. Karlis, and G. Wets, "Studying the effect of weather conditions on daily crash counts using a discrete time-series model," Accident Analysis \& Prevention, vol. 40, no. 3, pp. 1180-1190, 2008.

[7] Close COST Action 353, "New developments for winter service on European roads," Final Report of COST Action 353, Winter Service Strategies for Increased European Road Safety, Gdańsk, Poland, 2008.

[8] F. Malin, I. Norros, and S. Innamaa, "Accident risk of road and weather conditions on different road types," Accident Analysis \& Prevention, vol. 122, pp. 181-188, 2019.

[9] L. Fu, "An adaptive routing algorithm for in-vehicle route guidance systems with real-time information," Transportation Research Part B: Methodological, vol. 35, no. 8, pp. 749-765, 2001.

[10] A. Kanafani and H. Al-Deek, "A simple model for route guidance benefits," Transportation Research Part B: Methodological, vol. 25, no. 4, pp. 191-201, 1991.

[11] H. K. Lo and W. Y. Szeto, "A methodology for sustainable traveler information services," Transportation Research Part B: Methodological, vol. 36, no. 2, pp. 113-130, 2002.

[12] P. Thakuriah and A. Sen, "Quality of information given by advanced traveler information systems," Transportation Research Part C: Emerging Technologies, vol. 4, no. 5, pp. 249266, 1996.

[13] Y. Wang, M. Papageorgiou, G. Sarros, and W. J. Knibbe, "Real-time route guidance for large-scale express ring-roads," in Proceedings of the IEEE Intelligent Transportation Systems Conference, Toronto, Ontario, Canada, October 2006.

[14] P. W. Bonsall and M. Joint, "Driver compliance with route guidance advice: the evidence and its implications," in Proceedings of the Vehicle Navigation and Information Systems Conference, Troy, MI, USA, October 1991.
[15] W. Janssen and R. V. D. Horst, "Descriptive information in variable route guidance messages," in Proceedings of the $3 \mathrm{rd}$ Vehicle Navigation and Information Systems Conference, Oslo, Norway, September 1992.

[16] L. N. Boyle and F. Mannering, "Impact of traveler advisory systems on driving speed: some new evidence," Transportation Research Part C: Emerging Technologies, vol. 12, no. 1, pp. 57-72, 2004.

[17] J. Steenbruggen, M. T. Borzacchiello, P. Nijkamp, and H. Scholten, "Data from telecommunication networks for incident management: an exploratory review on transport safety and security," Transport Policy, vol. 28, pp. 86-102, 2013.

[18] H. L. Khoo and K. S. Asitha, "User requirements and route choice response to smart phone traffic applications (apps)," Travel Behaviour and Society, vol. 3, pp. 59-70, 2016.

[19] C. H. Yang, S. B. Kim, C. J. Yoon, J. G. Kim, J. H. Park, and D. G. Yun, "Analysis of road surface temperature change patterns using machine learning algorithms," International Journal of Highway Engineering, vol. 19, no. 2, pp. 35-44, 2017.

[20] C. H. Yang, C. J. Yoon, J. G. Kim, J. H. Park, and D. G. Yun, "Reliability of change patterns of road surface temperature and road segmentation based on road surface temperature," International Journal of Highway Engineering, vol. 18, no. 4, pp. 1-8, 2016.

[21] J. G. Kim, C. H. Yang, S. B. Kim, D. G. Yun, and J. H. Park, "Developing models for patterns of road surface temperature change using road and weather conditions," International Journal of Highway Engineering, vol. 20, pp. 127-135, 2018.

[22] J. G. Kim, C. H. Yang, H. J. Ryu, and J. P. Moon, "Performance analysis of model for road surface temperature change pattern by road section," International Journal of Highway Engineering, vol. 20, no. 5, pp. 121-128, 2018.

[23] S. Zhong, L. Zhou, S. Ma, and J. Ning, "Effects of different factors on drivers' guidance compliance behaviors under road condition information shown on VMS," Transportation Research Part A Policy and Practice, vol. 46, no. 9, pp. 1490-1505, 2012.

[24] D. S. Oh, Y. T. Oh, S. G. Jo, and E. J. Hong, "An analysis on service usage of traffic information on the expressway," The Journal of The Korea Institute of Intelligent Transport Systems, vol. 9, pp. 12-25, 2009.

[25] E. Dabbour, S. Easa, and M. Haider, "Using fixed-parameter and random-parameter ordered regression models to identify significant factors that affect the severity of drivers' injuries in vehicle-train collisions," Accident Analysis \& Prevention, vol. 107, pp. 20-30, 2017.

[26] T. Cherry and C. Townsend, "Assessment of potential improvements to metro-bus transfers in Bangkok, Thailand," Transportation Research Record, vol. 2276, no. 2276, pp. 116-122, 2012.

[27] J. Zmud, I. N. Sener, and J. Wagner, "Self-driving vehicles: determinants of adoption and conditions of usage," Transportation Research Record, vol. 2565, no. 1, pp. 57-64, 2016.

[28] M. Wang, E. W. Martin, and S. A. Shaheen, "Carsharing in Shanghai, China: analysis of behavioral response to local survey and potential competition," Transportation Research Record, vol. 2319, no. 1, pp. 86-95, 2012.

[29] SPSS Inc, PASW Statistics for Windows, SPSS Inc, Chicago, IL, USA, 2009.

[30] F. E. Harrell, "Ordinal logistic regression," in Regression Modeling Strategies. Springer Series in StatisticsSpringer, Berlin, Germany, 2015. 
[31] Samsung Traffic Safety Research Institute, Analysis of the Relationship between Regional Climate Changes and Traffic Accidents, Samsung Traffic Safety Research Institute, Seoul, Korea, 2016.

[32] S. J. Lee, "A study on factors that influence traffic accident severity in road surface freezing," Journal of the Korean Society of Safety, vol. 32, pp. 150-156, 2017. 